\title{
CCM3/SERPINI1 bidirectional promoter variants in patients with cerebral cavernous malformations: a molecular and functional study
}

Concetta Scimone ${ }^{1,2}$, Placido Bramanti ${ }^{3}$, Alessia Ruggeri ${ }^{1}$, Luigi Donato ${ }^{1,2}$, Concetta Alafaci ${ }^{1}$, Concetta Crisafulli ${ }^{1}$, Massimo Mucciardi ${ }^{4}$, Carmela Rinaldi ${ }^{1}$, Antonina Sidoti ${ }^{1,2^{*}}$ and Rosalia D'Angelo ${ }^{1}$

\begin{abstract}
Background: Cerebral cavernous malformations (CCMs) are vascular anomalies of the nervous system mostly located in the brain presenting sporadically or familial.

Causes of familial forms are mutations in CCM1 (Krit1), CCM2 (MGC4607) and CCM3 (PDCD10) genes. Sporadic forms with no affected relative most often have only one lesion and no germ line mutations. However, a number of sporadic cases with multiple lesions have been reported and are indeed genetic cases with a de novo mutation or a mutation inherited from an asymptomatic parent.

Methods: Here, we performed an analysis of regulatory region of CCM genes in 60 sporadic patients, negative for mutations in coding region and intron-exon boundaries and large deletion/duplications in CCM genes by direct sequencing and MLPA. Among 5 variants identified in 851-bp region shared by CCM3 and SERPIN/1 genes and acting as asymmetric bidirectional promoter, two polymorphisms c.-639 T > C/rs9853967 and c.-591 T > C/rs11714980 were selected. A case-control study was performed to analyze their possible relationships with sporadic CCMs. Promoter haplotypes activities on CCM3/SERPIN/1 genes expression were tested by dual-luciferase assay.

Results: No variants were identified in CCM1 and CCM2 regulatory regions. In CCM3/SERPINI1 asymmetric bidirectional promoter 5 variants, 2 of them unknown and 3 corresponding to polymorphisms C.-639 T > C/rs9853967, c.-591 T > C/rs11714980 and c.-359G > A/rs9834676 were detected. While rs9853967 and rs11714980 polymorphisms fall in a critical regulatory fragment outside the minimal promoter in intergenic region, other variants had no effects on transcription factor binding according to RegRNA tool. Case-control study performed on 60 patients and 350 healthy controls showed frequencies of the mutated alleles significantly higher in the control group than in patients. Furthermore, the functional assay showed a significant reduction of CCM3 expression for C-C haplotype even more than for T-C and C-T haplotypes. In SERPIN/1 direction, the reduction was not statistically significant.
\end{abstract}

Conclusions: Our data indicated that rs9853967 and rs 11714980 polymorphisms could be associated with a protective role in CCM disease.

Keywords: Bidirectional promoter, CCM3/SERPINI1, Polymorphism, Association study, Dual luciferase-assay, CCM genes

\footnotetext{
*Correspondence: asidoti@unime.it

'Department of Biomedical and Dental Sciences and Morphofunctional Imaging, Division of Medical Biotechnologies and Preventive Medicine, University of Messina, via C. Valeria 1, 98125 Messina, Italy

${ }^{2}$ Department of Cutting-Edge Medicine and Therapies, Biomolecular

Strategies And Neuroscience, Section of Neuroscience-applied, Molecular

Genetics and Predictive Medicine, I.E.ME.S.T, Palermo, Italy

Full list of author information is available at the end of the article
} 


\section{Background}

Cerebral cavernous malformations (CCMs) are among the most common cerebral vascular anomalies characterized by clusters of enlarged blood vessels consisting of a single layer of endothelium and lacking smooth muscle and elastic tissue, without intervening brain parenchyma $[1,2]$. CCMs, reported in up to $0.5 \%$ of the population, are primarily found within the central nervous system where they result in increased risk for stroke, seizures, recurrent headaches and focal neurological deficits [1-4]. CCMs are associated with loss-of-function mutations in any one of the three CCM genes CCM1/KRIT1, CCM2/ MGC4607 or CCM3/PDCD10 and occur in both sporadic and familial forms [5], inherited in an autosomal dominant fashion with a high penetrance.

Familial CCM accounts for only $20 \%$ of cases but tends to be more severe than sporadic CCM [1], with patients exhibiting multiple lesions and increased hemorrhage rates.

More than 150 distinct CCM1, CCM2, and CCM3 germline mutations are known [6-9].

Linkage analyses predicts that $40 \%$ of patients with familial forms is linked to CCM1 locus, $40 \%$ to CCM3 and, only $20 \%$ to CCM2 [10-13]; however, according with reported experimental data, these frequencies are not confirmed by an our recent screening of a cohort of Italian patients with CCMs [9]. Our data showed that $54 \%$ of patients leads CCM1 mutations, a very lower percent was observed for CCM3 (6 \%) while $18 \%$ leads mutation at CCM2 locus; the absence of any mutation in $22 \%$ of patients, leads to consider other possible elements involving in the development of disease like a somatic mosaicism of a de novo mutation that occurred during gestation and is not detectable in DNA extracted from peripheral blood $[5,6,14]$, the possibility of large deletions or duplications not detected by direct sequencing or mutations located in regulatory regions of CCM genes, and finally, the existence of other as yet unidentified genes.

No data in the literature exist on CCM genes regulatory regions. Therefore we focused our attention on molecular analysis of these regions in a cohort of CCM sporadic patients.

Initially we examined the promoters of CCM1 and CCM2 genes, located about $4.0 \mathrm{~kb}(C C M 1)$ and $0.5 \mathrm{~Kb}$ (CCM2) upstream from the ATG start codon, and finally CCM3 one. This is an evolutionary conserved bidirectional promoter shared with SERPINI1 gene, coding for a serine protease inhibitor [15]. Two genes were found to be closely adjacent to each other in a head-to-head orientation and separated by an exceptionally short intergenic region of 851-bp that function as a bidirectional promoter to regulate transcription of both genes. A 175-bp fragment from nt1 to 175 in the vicinity of
CCM3 was further determined to function as a minimal bidirectional promoter. A critical regulatory fragment, from nt 176-473 outside the minimal promoter in the intergenic region, was identified to contain a strong repressive element for SERPINI1 and an enhancer for CCM3 [15]. In a parallel study, through an in-silico approach, we investigated the existence of common pathways to both genes in order to explain the need of this co-regulation and to detect a possible involvement of SERPINI1 in CCM pathogenesis (data not shown).

Here, we focused on intergenic region of $851 \mathrm{bp}$ shared by CCM3 and SERPINI1, where we identified 5 variants, 2 of them unknown (c.-964 G>C and c. $-419 \mathrm{G}>\mathrm{T}$ ) and 3 corresponding to polymorphisms: c. $639 \mathrm{~T}>\mathrm{C} / \mathrm{rs} 9853967, \quad$ c. $\quad-591 \quad \mathrm{~T}>\mathrm{C} / \mathrm{rs} 11714980$ and c. $-359 \mathrm{G}>\mathrm{A} / \mathrm{rs} 9834676$.

RegRNA analysis showed that the rs9834676 polymorphism and two novel variants do not affect the transcriptional regulatory motifs. Furthermore, literature data report rs9853967 and rs11714980 polymorphisms falling in a critical regulatory fragment outside the minimal promoter in intergenic region [15].

Therefore, our attention has focused on rs9853967 and rs11714980 polymorphisms and their possible association with CCM disease. A case-control study was carried-out and the polymorphisms effects on two genes expression were determined by a functional assay.

\section{Methods \\ Subjects}

A total of 60 CCM patients (40\% men, $60 \%$ women) were recruited during 2003-2013.

Detailed clinical and neuroimaging information on patients and their relatives were collected through direct interview by review of the medical charts, before CCM gene molecular analysis and after providing their written informed consent. On the basis of pedigree analysis and in the absence of relatives positive to biomolecular investigation and/or Magnetic Resonance Imaging (MRI) (standard spin echo and fast turbo spin echo T1- and T2-weighted axial, coronal, and/or sagittal images) the patients were considered sporadic. Lesions were single in 58 patients $(97.0 \%)$ and multiple in 2 patients $(3.0 \%)$.

The age of symptoms onset, in all patients examined, coincides with the age at diagnosis and the patient's age at the time of recruitment. The mean age at onset of symptoms was $39,5 \pm 18,7$ years (median, 36.0 years; range, 10-73 years) (Table 1). A group consisted of 350 unrelated, randomly selected, ethnically matched, healthy individuals were recruited. Demographic data on controls are summarized in Table 1. Age at symptoms onset of male vs female was matched in the CCM patients, as well as age of male versus female in the controls. Control individuals were selected to match the 
Table 1 Demographic and disease data on CCM sporadic patients and controls

(A) CCM sporadic patients $(n=60)$

\begin{tabular}{lllll}
\multicolumn{5}{c}{ Age of symptoms onset } \\
Gender & $n$ & Mean \pm SD & Range & Lesion number \\
Male & 24 & $35,6 \pm 19,1$ & $10-71$ & $2 / 60>1$ lesion \\
Female & 36 & $42,2 \pm 18,3$ & $15-73$ & \\
Overall & 60 & $39,5 \pm 18,7$ & $10-73$ & \\
$\begin{array}{llll}\text { Male + Female } \\
\text { (asymptomatic) }\end{array}$ & $2+2$ & & &
\end{tabular}

(B) Healthy controls $(n=350)$

\begin{tabular}{llll} 
& $n$ & & Age \\
Male & 204 & $44,3 \pm 17,9$ & Range \\
Female & 146 & $42,3 \pm 18,3$ & $12-73$ \\
Overall & 350 & $43,5 \pm 18,1$ & $12-73$ \\
\hline
\end{tabular}

$p>0.05$ indicates no significant differences. Statistical analysis was tested by the Student's $t$-test. CCM, cerebral cavernous malformation; $S D$, standard deviation The age of symptoms onset in all patients (with the exception of asymptomatic patients) coincides with the age at diagnosis

CCM patients for age. Table 1 indicates no significant differences $(p>0.05)$. This study was approved by the Scientific Ethics Committee of the Azienda Ospedaliera Universitaria-Policlinico 'G. Martino' Messina. Informed consent was obtained from all patients and controls.

Genetic analysis of the CCM1, CCM2 and CCM3 promoters DNA was extracted from leukyocytes by using the standard protocols. The amplification of regulatory regions of CCM1 and CCM2 genes was performed using the primers pairs designed according to the published nucleotide sequence of GenBank (accession no. NG_012964.1 CCM1; NG_016295.1 CCM2) (Table 2).

Polymerase chain reaction (PCR) was carried out in a thermal cycler (Gene Amp PCR System 2700; PE Applied Biosystems, Foster City, CA) under following conditions:

Table 2 Primers for PCR amplification of CCM genes promoter regions

\begin{tabular}{lll}
\hline & Primer set & Anneal $\left({ }^{\circ} \mathrm{C}\right)$ \\
\hline${ }^{a}$ CCM1 & F: 5' - ACA GAC AGA ACA ACA ATG CTC - 3' & 58 \\
& R: 5' - TCA CTG GAC CTG CAG TCT CT - 3' & \\
${ }^{a}$ CCM2 & F: 5' - TT ACA TTC TAG CTG TGC TA - 3' & 49 \\
& R: 5' - CTG GAC AGG TGC GTT CTC - 3' & \\
CCM3- SERPINI1 & F: 5' - TGAGGCACTGACTTCACTT-3' & 58 \\
& R: 5'-CTTAGCTGCTCTCAGGGA-3' (P1) & \\
& F: 5' - TCCCTGAGAGCAGCTAAG-3' & 56 \\
& R: 5' - GCTCTCGTTCCTGCTTC-3' (P2) & \\
\hline
\end{tabular}

aprimers were designed to amplify a promoter region located about $3.8 \mathrm{~kb}$ (CCM1) and $0.5 \mathrm{~kb}$ (CCM2) from the ATG start codon
$0.8 \mu \mathrm{g}$ of genomic DNA was added to $50 \mu \mathrm{l}$ reaction mixture containing a $0.2 \mu \mathrm{m}$ concentration of each primer and $1 \mathrm{U}$ Taq Gold polymerase (PE Applied Biosystems).

PCR conditions for CCM1 promoter region (655 bp) were as follows: denaturation at $95{ }^{\circ} \mathrm{C}$ for $45 \mathrm{~s}$, annealing at $58{ }^{\circ} \mathrm{C}$ for $35 \mathrm{~s}$ and extension at $72{ }^{\circ} \mathrm{C}$ for $40 \mathrm{~s}$ for 35 cycles, after an initial $10 \mathrm{~min}$ denaturation at $95^{\circ} \mathrm{C}$.

For CCM2 promoter region (620 bp) we employed these conditions: one cycle of denaturation at $95{ }^{\circ} \mathrm{C}$ for $10 \mathrm{~min}$, followed by 35 cycles at $94{ }^{\circ} \mathrm{C}$ for $40 \mathrm{~s}, 49^{\circ} \mathrm{C}$ for $30 \mathrm{~s}$, and $72{ }^{\circ} \mathrm{C}$ for $45 \mathrm{~s}$, before a final extension at $72{ }^{\circ} \mathrm{C}$ for $10 \mathrm{~min}$.

Short intergenic region (851 bp) between two nonhomologous genes, SERPINI1 and CCM3, was amplified using two primer sets designed according to published sequence data (Accession no. NG_ 008217.1 for SERPINI1; NG_008158.1 for CCM3) and shown in Table 2.

Two fragments of $580 \mathrm{bp}$ (P1) and $383 \mathrm{bp}$ (P2) were amplified under following conditions: for P1 denaturation at $94{ }^{\circ} \mathrm{C}$ for $50 \mathrm{~s}$, annealing at $58{ }^{\circ} \mathrm{C}$ for $45 \mathrm{~s}$ and extension at $72{ }^{\circ} \mathrm{C}$ for $50 \mathrm{~s}$ for 35 cycles, after an initial $10 \mathrm{~min}$ denaturation at $95{ }^{\circ} \mathrm{C}$; for $\mathrm{P} 2$ denaturation at $94{ }^{\circ} \mathrm{C}$ for $40 \mathrm{~s}$, annealing at $56{ }^{\circ} \mathrm{C}$ for $35 \mathrm{~s}$ and extension at $72{ }^{\circ} \mathrm{C}$ for $45 \mathrm{~s}$ for 35 cycles, after an initial $10 \mathrm{~min}$ denaturation at $95{ }^{\circ} \mathrm{C}$.

PCR products were sequenced by direct sequencing. The nucleotide number relative to polymorphisms identified in intergenic region of $851 \mathrm{bp}$ was indicated respect to the transcriptional start sites of the reference sequence reported by the NCBI database (in direction of SERPINI1).

\section{Statistical analysis}

Analysis of data was performed using computer software Statistical Package for Social Science (SPSS) for Windows (Version 6.0.1) and Epi Info (version 6.0.4).

Comparisons between means of age of symptoms onset of male versus female in the CCM group and overall CCM age at onset versus overall healthy control age were calculated with the Student's $t$-test. For each group (control and patients), allele frequencies were calculated by direct gene counting. Estimates of statistical significance were calculated by standard $\chi^{2}$ analysis for one degree of freedom. Descriptive analysis included Student's $t$-test of means and the respective standard deviation (SD) for cases and controls. A two-sided probability value of $<0.05$ was considered to indicate statistical significance. The results from dual-luciferase assay were compared using one-way ANOVA for repeated measurements.

In silico analysis

RegRNA (http://regrna.mbc.nctu.edu.tw/html/prediction.html) [16], a transcription factor prediction tool, was used to 
to evaluate how the identified variants could interfere with the transcriptional regulatory motifs in CCM3/ SERPINI1 promoter.

The relative position numbers of the nucleotides in this intergenic region of $851 \mathrm{bp}$ was as follows: $9(-$ c.964G $>$ C), 335 (-c.-639 T > C), 383 (-c.-591 T >C), 556 (- c.419 G > T), 615 (-c.-359G > A).

\section{Functional studies \\ Cell culture}

U373-MG (human, Caucasian, glioblastoma-astrocytoma) cells were cultured in Dulbecco's modified Eagle's medium (DMEM) supplemented with $10 \%$ Fetal Bovine Serum (FBS), $100 \mathrm{U} / \mathrm{ml}$ of penicillin and $1 \mathrm{mg} / \mathrm{ml}$ of streptomycin (Lonza) at $37{ }^{\circ} \mathrm{C}$ in a water-satured atmosphere with $5 \%$ $\mathrm{CO}_{2}$.

\section{Construction of the reporter gene plasmids}

To examine the potential effects of the c. $-639 \mathrm{~T}>\mathrm{C}$ and c.-591 $\mathrm{T}>\mathrm{C}$ on the intergenic region of 851 bp transcription activity, we compared the promoter activity of four common haplotypes (c.-639 T/c.-591 T) (T-T), (c.639C/c.-591 T) (C-T), (c.-639 T/c.-591C) (T-C), (c.639C/c.-591C) (C-C). $851 \mathrm{bp}$ intergenic regions were amplified by PCR using genomic DNA from donors carrying each haplotype, using the primers showed in the Table 3 and under the following conditions: 1 cycle of $95{ }^{\circ} \mathrm{C}$ for $5 \mathrm{~min} ; 35$ cycles of $94{ }^{\circ} \mathrm{C}$ for $40 \mathrm{~s}, 53{ }^{\circ} \mathrm{C}$ for $35 \mathrm{~s}$, and $72{ }^{\circ} \mathrm{C}$ for $40 \mathrm{~s}$; and $1 \mathrm{cycle}$ of $72{ }^{\circ} \mathrm{C}$ for $10 \mathrm{~min}$.

PCR products were inserted upstream of the luciferase gene cloned into the pGL4.10 (luc2).

For this purpose, PCR products, as well as pGL4.10 (luc2) were digested with BglII and HindIII (Promega) and then purified (PureLink ${ }^{\mathrm{TM}}$ PCR Purification Kit, Life Technologies). Vector arms were ligated overnight to the digested PCR fragment. The novel constructs were subcloned into E. coli Top 10 cells (Life Technologies) and single colonies were miniprep. The correct sequence of all the clones was verified by DNA sequencing.

\section{Transient transfection and promoter assays}

Cells were first seeded in 96-well culture plates at a density of $2 \times 10^{4}$ cells per well. In each well, cells were then co-transfected with $0.6 \mu$ l of FuGENE HD Transfection Reagent (Promega) and a mixture consisting of $0.2 \mu \mathrm{g}$ of the pGL4.10 [luc2] promoter constructs and $0.02 \mu \mathrm{g}$ of the co-reporter vector pGL4.74 [hRluc/TK] in a serum-free medium and then incubated for $24 \mathrm{~h}$ at
$37{ }^{\circ} \mathrm{C}$ in a humidified atmosphere of $5 \% \mathrm{CO}_{2}$ in air. After incubation, cells were washed twice with PBS and lysed by Passive Lysis Buffer (Promega). Luciferase activity was measured using Dual Luciferase assay kit (Promega) and GloMax-Luminometer (Promega). Reporter construct activity was normalized by comparison with activity from the Renilla luciferase construct. Luciferase activities are representative of at least three independent experiments, with each construct tested in triplicate per experiment.

\section{Results}

Genotype and allele frequencies of c.-639 T > C/ rs9853967 and C.-591 T > C/ rs11714980 polymorphisms in patients and controls

In the promoter regions of CCM1 and CCM2 of 60 CCM patients cohort, no variants has been identified.

Conversely, analysis of regulatory intergenic region shared by CCM3 and SERPINI1 has lead to the identification of 5 variants, 2 unknown (c.-964 G>C and c.419G > T) and 3 reported such as polymorphisms in SNP database (http://www.ensembl.org/Homo_sapiens/Gene/ Sequence?db=core;g=ENSG00000163536;.r=3:167453031167543356: c. $-639 \mathrm{~T}>\mathrm{C} / \mathrm{rs} 9853967, \quad$ c. $-591 \quad \mathrm{~T}>\mathrm{C} /$ rs11714980 and c.-359 G > A/rs9834676).

To evaluate the possible influence that these variants could have on transcriptional regulatory motifs, wild-type (c.- $964 G$, c.-639 T, c. -591 T- c. -419 G, c.-359G) and mutated (c.- $964 \mathrm{C}$, c. -639 C, c. $-591 \mathrm{C}$, c. -419 T, c.-359A) sequences of intergenic region shared by CCM3 and SERPINI1 were analyzed by using RegRNA. In mutated sequence the loss of transcriptional regulatory motif located in position 334 338 (RegRNA ID:R0146) was detected (http://regrna.mbc.nctu.edu.tw/php/showtable.php?ColorRegion $=\&$ FileDir $=$ tmp $/ 20160620 / 200730 \&$ SeqID $=200730$ \&MotifInfo=Transcriptional\%20Regulatory\%20Motifs\& MotifType $=$ tfbs) respect to wild-type one (http://regrna. mbc.nctu.edu.tw/php/showtable.php?ColorRegion=\&FileDir $=$ tmp $/ 20160620 / 200521 \&$ SeqID $=200521 \&$ MotifInfo=Transcriptional\%20Regulatory\%20Motifs\&MotifType=tfbs). To exclude a possible role of variants c.-964 $\mathrm{G}>\mathrm{C}$, c. $-419 \mathrm{G}>\mathrm{T}$ and c. $-359 \mathrm{G}>\mathrm{A}$ in the loss of this motif a further analysis was performed: the motif was absent also in (c.- 964G, c.-639C, c.-591C, c.-419G,c.-359G) sequence, assigning to c. $639 \mathrm{~T}>\mathrm{C}$ and c.$591 \mathrm{~T}>\mathrm{C}$ polymorphisms a role in the loss (http:// regrna.mbc.nctu.edu.tw/php/showtable.php?ColorRegion $=\&$ FileDir $=$ tmp $/ 20160620 / 204528 \&$ SeqID $=204528$

Table 3 Primer sequences used to amplify CCM3 promoter region for subsequent cloning

\begin{tabular}{lll}
\hline & Primer sequence \\
\hline SERPINI1 (1-851) & F: 5'ATAGATCTACTCCGGCGACGCCGGA-3' & R: 5'ATAAGCTTGTCCAGACTGCGCCTCT-3' \\
CCM3 (851-1) & F: 5'-ATAGATCTGTCCAGACTGCGCCTCT-3' & R: 5'-ATAAGCTTACTCCGGCGACGCCGGA-3' \\
\hline
\end{tabular}


Table 4 Allele and genotype frequencies of CCM3-SERPINI1 promoter polymorphisms

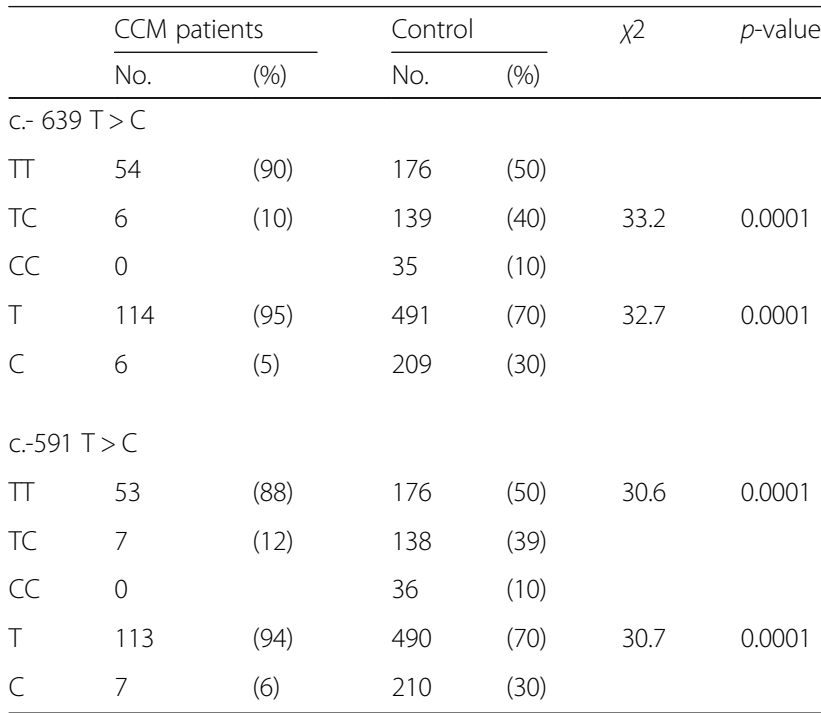

Position relative to the first position of the starting codon ATG (in direction of SERPINI1)

\&MotifInfo=Transcriptional\%20Regulatory\%20Motifs\&MotifType $=$ tfbs). Furthermore, literature data report rs9853967 and rs11714980 polymorphisms falling outside the minimal promoter (from nt 176-473) in a critical regulatory element identified to contain a strong repressive element for SERPINI1 and an enhancer for CCM3 [15].

Because no data about these polymorphisms and CCM there are in literature and few data about polymorphisms association and CCM too [17], we focused our attention on above mentioned rs9853967 and rs11714980.

First, we analyzed c.-639 T > C/ rs9853967, c.-591 T > $\mathrm{C} / \mathrm{rs} 11714980$ polymorphisms frequencies in a group of CCM sporadic patients vs a healthy control sample. Genotype distribution is given in Table 4. About the $-639 \mathrm{~T}>\mathrm{C} / \mathrm{rs} 9853967$ polymorphism, 35/350 (10 \%) controls typed were homozygous for the mutant ' $\mathrm{C}$ ' allele. None was found to be homozygous in the patient group; 6 heterozygotes (10\%) were found among 60 CCM patients vs the 139/350 (40 \%) in control group.

The frequency of the ' $\mathrm{C}$ ' allele was 0.3 for controls and 0.05 for patients $\left(\chi^{2}=32.7 ; \mathrm{p}=0.0001\right)$.

Same trend was observed for c.-591 T > C/ rs11714980 polymorphism with "C" mutated allele having a frequency in CCM samples of $0.06 \%$.

The second step regarded the characterization of the effects of the c.-639 $\mathrm{T}>\mathrm{C} / \mathrm{rs} 9853967$ and c.-591 T >C/ rs11714980 polymorphisms.

For this purpose two constructs of 851 bp were made: toward the CCM3 and the SERPINI1 direction.

Promoter activity of the four common haplotypes (T-T, T-C, C-T and C-C) was compared. The T-C and $\mathrm{C}-\mathrm{T}$ haplotypes significantly decreased promoter activity compared with the T-T haplotype; $\mathrm{C}-\mathrm{C}$ haplotype showed largest reduction of promoter activity $(p<0.01)$. In both cases this reduction was only in CCM3 direction. In SERPINI1 direction, it was not statistically significant $(p>0.05)$ (Fig. 1).

\section{Discussion}

We performed a molecular analysis on CCM genes regulatory regions in a cohort of CCM sporadic patients negative for mutations in the coding regions of these genes as well as for large genomic rearrangements not detectable to direct sequencing.

Case-control study performed on 60 patients and 350 healthy controls showed a possible association with CCM disease. Frequencies of the mutated alleles were significantly higher in the control group than in patients suggesting a possible protective effect of two polymorphisms.

Dual-luciferase assay of the c.-639 $\mathrm{T}>\mathrm{C} / \mathrm{rs} 9853967$ and c.-591 $\mathrm{T}>\mathrm{C} / \mathrm{rs} 11714980$ polymorphisms falling in

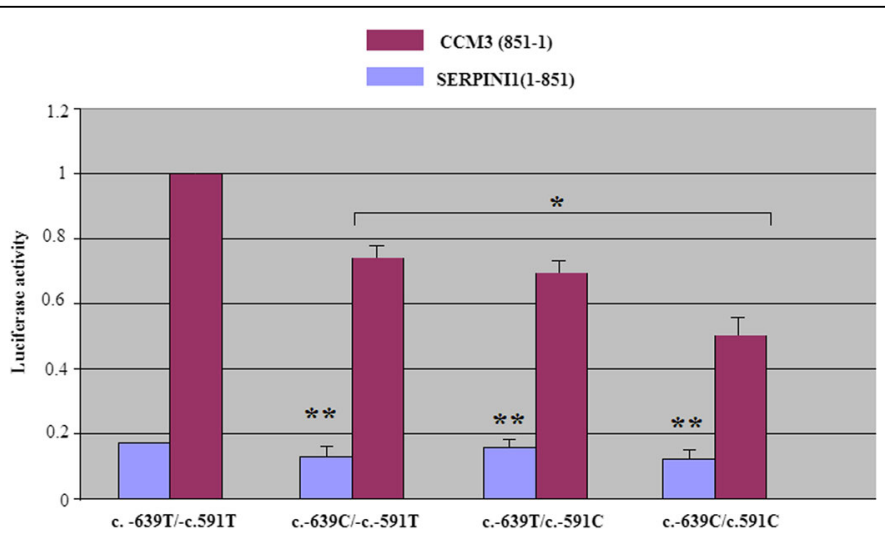

Fig. 1 Transcription activity analysis of CCM3/SERPINI1 haplotypes of the C.-639 T > C and c.-591 T>C polymorphisms. The transcription activity was measured using the Dual-Luciferase Reporter Assay System in U373 MG (human, Caucasian, glioblastoma-astrocytoma) cells. Luciferase activities are representative of at least three independent experiments, with each construct tested in triplicate per experiment. ${ }^{*} p<0.01$; ${ }^{* *} p>0.05$ 
the critical regulatory fragment of bidirectional promoter SERPINI1 and CCM3, showed a significant reduction of CCM3 expression for $\mathrm{C}-\mathrm{C}$ haplotype even more than for T-C and C-T haplotypes. In SERPINI1 direction, the reduction was not statistically significant.

CCM3 reduced expression would seem to disagree with case-control study data showing a higher frequency of the mutated alleles in control group than in patients. This taking into account the only apoptotic role of CCM3 protein and the association between CCM3 lossof-function mutations and CCM development $[18,19]$.

Evidences suggest that CCM3 interacts with CCM1 and CCM2 proteins in an intracellular complex sharing some common signaling pathways [20-23].

Furthermore, it is involved in angiogenesis and remodeling of cerebral vessels. Thus CCM3 protein acts as a positive regulator of Ste20-related kinase MST4 [24] promoting cell growth and transformation via extracellular signal-regulated kinase (ERK) pathway.

These processes are the basis of pathogenesis, progression, and oncogenic behavior of human cancers [25] as well as of CCM pathogenesis. Furthermore, it was shown that potent short interfering RNAs (siRNAs) against CCM3 and MST4 are able to specifically inhibit the expression of CCM3 and MST4 mRNA, respectively [26-28].

Therefore, based on these observations it is possible to assume that c.-639 $\mathrm{T}>\mathrm{C} / \mathrm{rs} 9853967$ and c.-591 $\mathrm{T}>\mathrm{C}$ polymorphisms in regulatory intergenic region shared by CCM3 and SERPINI1 genes could have a protective role against CCM pathogenesis. In fact, two polymorphisms cause a considerable reduction of $C C M 3$ expression to dual luciferase-assay, thus justifying the higher frequencies of mutated alleles found in the control group than in patients. The reduced expression of CCM3 gene we observed might be accompanied by reduced ERK activity and attenuated cell growth. Further studies are needed to confirm this.

\section{Conclusions}

In the present study, for the first time, we found that c.-639 $\mathrm{T}>\mathrm{C} / \mathrm{rs} 9853967$ and c.-591 $\mathrm{T}>\mathrm{C} / \mathrm{rs} 11714980$ polymorphisms in CCM3/SERPINI1 genes asymmetric bidirectional promoter were able to determine a sensible reduction of CCM3 expression. Mutated allelic frequencies higher in control group than in patients and the reduction of CCM3 expression especially in C-C haplotype carriers suggesting a possible protective role of these polymorphisms in CCM pathogenesis.

\section{Abbreviations}

CCMs: Cerebral cavernous malformations; DMEM: Dulbecco's modified Eagle's medium; ERK: Extracellular signal-regulated kinase; FBS: Fetal Bovine Serum; MRI: Magnetic resonance imaging; PCR: Polymerase chain reaction; SD: Standard deviation; siRNAs: Short Interfering RNAs; SPSS: Statistical package for social science
Funding

No financial support is present for the authors.

\section{Availability of data and materials}

The data supporting the findings have been provided in the manuscript. Any further information can be made available on request to the corresponding author.

\section{Authors' contributions}

CS: carried out the genetic analysis, writing and revision of the manuscript PB: has been working on recruitment of cases as neurologist AR: carried out the functional studies LO: carried out the genetic analysis CA: has been working on recruitment of cases as neurosurgeon and provided clinical details CC: has been working on statistical analysis MM: has been working on statistical analysis CR: provided to acquisition of data and sequence alignment RD: design and conceptualization of the study, drafting of manuscript AS: design and conceptualization of the study, revising the manuscript. All authors read and approved the final manuscript.

\section{Competing interests}

The authors declare that they have no competing interests.

\section{Consent for publication}

All the authors agree to publication.

\section{Ethics approval and consent to partecipate}

This study was approved by the Scientific Ethics Committee of the Azienda Ospedaliera Universitaria- Policlinico 'G. Martino' Messina. Informed consent was obtained from all patients and controls.

\section{Author details}

${ }^{1}$ Department of Biomedical and Dental Sciences and Morphofunctional Imaging, Division of Medical Biotechnologies and Preventive Medicine, University of Messina, via C. Valeria 1, 98125 Messina, Italy. ${ }^{2}$ Department of Cutting-Edge Medicine and Therapies, Biomolecular Strategies And Neuroscience, Section of Neuroscience-applied, Molecular Genetics and Predictive Medicine, I.E.ME.S.T, Palermo, Italy. ${ }^{3}$ IRCCS Centro Neurolesi "Bonino-Pulejo", Messina, Italy. "Department of Economy, University of Messina, Messina, Italy.

Received: 9 June 2015 Accepted: 29 September 2016

Published online: 13 October 2016

\section{References}

1. Cavalcanti DD, Kalani MY, Martirosyan NL, Eales J, Spetzler RF, Preul MC. Cerebral cavernous malformations: from genes to proteins to disease. J Neurosurg. 2012;116:122-32.

2. Fischer A, Zalvide J, Faurobert E, Albiges-Rizo C, Tournier-Lasserve E. Cerebral cavernous malformations: from CCM genes to endothelial cell homeostasis. Trends Mol Med. 2013;19:302-8.

3. Zabramski JM, Wascher TM, Spetzler RF, Johnson B, Golfinos J, Drayer BP, et al. The natural history of familial cavernous malformations: results of an ongoing study. J Neurosurg. 1994;80(3):422-32.

4. Zabramski JM, Henn JS, Coons S. Pathology of cerebral vascular malformations. Neurosurg Clin N Am. 1999;10(3):395-410.

5. Riant F, Bergametti F, Ayrignac X, Boulday G, Tournier-Lasserve E. Recent insights into cerebral cavernous malformations: the molecular genetics of CCM. FEBS J. 2010;277:1070-5.

6. Liquori $\mathrm{CL}$, Berg MJ, Siegel AM, Huang E, Zawistowski JS, Stoffer TP. Mutations in a Gene Encoding a Novel Protein Containing a Phosphotyrosine-Binding Domain Cause Type 2 Cerebral Cavernous Malformations. Am J Hum Genet. 2007:80:69-75.

7. Battistini S, Rocchi R, Cerase A, Citterio A, Tassi L, Lando G, et al. Clinical, magnetic resonance imaging, and genetic study of 5 Italian families with cerebral cavernous malformation. Arch Neurol. 2007;64:843-8.

8. Cavé-Riant F, Denier C, Labauge P, Cécillon M, Maciazek J, Joutel A, et al. Spectrum and expression analysis of KRIT1 mutations in 121 consecutive and unrelated patients with Cerebral Cavernous Malformations. Eur J Hum Genet. 2002;10:733-40. 
9. D'Angelo R, Marini V, Rinaldi C, Origone P, Dorcaratto A, Avolio M, et al. Mutation analysis of CCM1, CCM2 and CCM3 genes in a cohort of Italian patients with cerebral cavernous malformation. Brain Pathol. 2011;21(2):215-24.

10. Craig HD, Günel M, Cepeda O, Johnson EW, Ptacek L, Steinberg GK, et al. Multilocus linkage identifies two new loci for a mendelian form of stroke, cerebral cavernous malformation, at 7p15-13 and 3q25.2-27. Hum Mol Genet. 1998;7:1851-8.

11. Günel M, Awad IA, Anson J, Lifton RP. Mapping a gene causing cerebral cavernous malformation to 7q11.2-q21. Proc Natl Acad Sci U S A. 1995;92(14):6620-4.

12. Dubovsky J, Zabramski JM, Kurth J, Spetzler RF, Rich SS, Orr HT, et al. A gene responsible for cavernous malformations of the brain maps to chromosome 7q. Hum Mol Genet. 1995;4:453-8.

13. Liquori CL, Berg MJ, Squitieri F, Ottenbacher M, Sorlie M, Leedom TP, et al. Low frequency of PDCD10 mutations in a panel of CCM3 probands: potential for a fourth CCM locus. Hum Mutat. 2006;27(1):118.

14. Gaetzner S, Stahl S, Sürücü O, Schaafhausen A, Halliger-Keller B, Bertalanffy $\mathrm{H}$, et al. CCM1 gene deletion identified by MLPA in cerebral cavernous malformation. Neurosurg Rev. 2007;30:155-9.

15. Chen PY, Chang WS, Chou RH, Lai YK, Lin SC, Chi CY, et al. Two nonhomologous brain diseases-related genes, SERPINI I and PDCD10, are tightly linked by an asymmetric bidirectional promoter in an evolutionarily conserved manner. BMC Mol Biol. 2007:8:2.

16. Huang $\mathrm{HY}$, Chien $\mathrm{CH}$, Jen $\mathrm{KH}$, Huang HD. RegRNA. A regulatory RNA motifs and elements finder. Nucleic Acids Res. 2006;34:W429-34.

17. D'Angelo R, Scimone C, Rinaldi C, Trimarchi G, Italiano D, Bramanti $P$, et al. CCM2 gene polymorphisms in Italian sporadic patients with cerebral cavernous malformation: a case-control study. Int J Mol Med. 2012;29(6):1113-20.

18. Bergametti F, Denier C, Labauge P, Arnoult M, Boetto S, Clanet M, et al. Mutations within the programmed cell death 10 gene cause cerebral cavernous malformations. Am J Hum Genet. 2005;76:42-51.

19. Guclu B, Ozturk AK, Pricola KL, Bilguvar K, Shin D, O'Roak BJ, et al. Mutations in apoptosis-related gene, PDCD10, cause cerebral cavernous malformation. Neurosurgery. 2005;57:1008-13.

20. Hilder TL, Malone MH, Bencharit S, Colicelli J, Haystead TA, Johnson GL, et al. Pro-teomic identification of the cerebral cavernous malformation signaling complex. J Proteome Res. 2007;6:4343-55.

21. Labauge P, Denier C, Bergametti F, Tournier-Lasserve E. Genetics of cavernous angiomas. Lancet Neurol. 2007;6:237-44.

22. Stahl S, Gaetzner S, Voss K, Brackertz B, Schleider E, Surucu O, et al. Novel CCM1, CCM2, and CCM3 mutations in patients with cerebral cavernous malformations: in-frame deletion in CCM2 prevents formation of a CCM1/CCM2/CCM3 protein complex. Hum Mutat. 2008;29:709-17.

23. Voss K, Stahl S, Schleider E, Ullrich S, Nickel J, Mueller TD, et al. CCM3 interacts with CCM2 indicating common pathogenesis for cerebral cavernous malformations. Neurogenetics. 2007;8:249-56.

24. Sugden PH, McGuffin LJ, Clerk A. SOcK, MiSTs, MASK and STicks: the GCKIII (germinal centre kinase III) kinases and their heterologous protein-protein interactions. Biochem J. 2013:454:13-30.

25. Sebolt-Leopold JS. Advances in the development of cancer therapeutics directed against the RAS-mitogen-activated protein kinase pathway. Clin Cancer Res. 2008;14(12):3651-6.

26. Lin JL, Chen HC, Fang HI, Robinson D, Kung HJ, Shih HM. MST4, a new Ste20-related kinase that mediates cell growth and transformation via modulating ERK pathway. Oncogene. 2001;20:6559-69.

27. Sung V, Luo W, Qian D, Lee I, Jallal B, Gishizky M. The Ste20 kinase MST4 plays a role in prostate cancer progression. Cancer Res. 2003;63:3356-63.

28. Ma X, Zhao H, Shan J, Long F, Chen Y, Chen Y, et al. PDCD10 interacts with Ste20-related kinase MST4 to promote cell growth and transformation via modulation of the ERK pathway. Mol Biol Cell. 2007;18(6):1965-78.

\section{Submit your next manuscript to BioMed Central and we will help you at every step:}

- We accept pre-submission inquiries

- Our selector tool helps you to find the most relevant journal

- We provide round the clock customer support

- Convenient online submission

- Thorough peer review

- Inclusion in PubMed and all major indexing services

- Maximum visibility for your research

Submit your manuscript at www.biomedcentral.com/submit 